\title{
Comunicação Libertadora no Século XXI
}

\section{Liberating Communication in the 21 st Century}

\author{
VENÍCIO A. DE LIMAa \\ Universidade Federal de Minas Gerais, Centro de Estudos Republicanos Brasileiros. \\ Belo Horizonte - MG, Brasil
}

\section{RESUMO}

Paulo Freire tem alguma contribuição a oferecer ao campo de estudos da comunicação nos nossos dias? Neste artigo, fazemos uma exaustiva leitura da obra de Freire, desde a sua visão da natureza humana, que inclui a comunicação como realidade existencial e ontológica, passando pela comunicação nas suas dimensões relacional e política. Fazemos também um levantamento das manifestações de Freire sobre comunicação após a publicação dos textos fundadores; da posição crítica de estudiosos da comunicação no Brasil e no exterior e, finalmente, oferecemos uma avaliação da contribuição de Freire na perspectiva de sua prática da liberdade alongada para a pesquisa da comunicação no século XXI.

Palavras-chave: Paulo Freire, comunicação libertadora, práxis da liberdade

\begin{abstract}
Does Paulo Freire have any contribution to the field of communication studies today? We offer an exhaustive reading of Freire's work, from his view of human nature, which includes communication as an existential and ontological reality, to communication in its relational and political dimensions. We also survey Freire's manifestations on communication after the publication of his foundational texts; an analysis of the critical position of communication scholars in Brazil and abroad; and, finally, an evaluation of Freire's contribution from the perspective of his praxis of freedom extended to communication research in the 21 st century.
\end{abstract}

Keywords: Paulo Freire, liberating communication, praxis of freedom 
Eu sonho com uma sociedade reinventando-se de baixo para cima, em que as massas populares tenham, na verdade, o direito de ter voz e não o dever apenas de escutar.

-Paulo Freire, Essa Escola Chamada Vida.

\section{INTRODUÇÃO}

NÚCLEO DO PENSAMENTO de Paulo Freire foi formado em sua
práxis de educador no Brasil do final dos anos 1950, início dos 1960 e
no exílio chileno, até o final da década. Nesse período, acreditava-se que o processo coletivo de conscientização, promovido através da educação como prática da liberdade, levaria à emancipação política e econômica de populações historicamente submetidas à injustiça e à desigualdade na América Latina. Essa utopia era compartilhada por parcela importante de cristãos - católicos e protestantes, incluindo Freire - estimulados pelo aggiornamento proposto pelo Papa João XXIII, pelas novas diretrizes emanadas do Concílio Vaticano II (1962-1965) e pela nascente Teologia da Libertação (Löwy, 2016). Mesmo depois do golpe civil-militar de 1964, no Brasil, e em meio à acirrada disputa ideológica promovida pela Guerra Fria, muitos ainda apostavam na viabilidade de um projeto de socialismo democrático para a região. Não aconteceu.

Preso duas vezes pela ditadura, Freire esteve exilado por mais de 15 anos na Bolívia, no Chile, nos Estados Unidos e na Suíça. Trabalhando no Conselho Mundial de Igrejas, teve, a partir de 1970, a oportunidade de colaborar com nações africanas recém-saídas de sangrentos processos de libertação nacional, regressando ao Brasil somente após a Lei de Anistia, em 1980.

Neste início da terceira década do século XXI, as circunstâncias históricas são totalmente diversas. Freire não chegou a viver os conturbados tempos da pós-verdade, das redes sociais virtuais e da disseminação descontrolada de fake news (desinformação). Quando faleceu, em 1997, o protagonismo dos oligopólios de mídia e sua capacidade de definir e influenciar o cenário das disputas políticas era inconteste. Muitos acreditavam, todavia, que a revolução digital e a internet seriam fatores incontornáveis de participação popular e fortalecimento da democracia. Não aconteceu.

Nos novos tempos, aqueles aos quais o cientista político franco-italiano Giuliano da Empoli (2019) chamou de "engenheiros do caos" alimentam a formação de bolhas virtuais que não se comunicam entre si. Sonegam-se do debate público as questões de interesse comum, rompendo uma condição básica do processo democrático. Entre outras diferentes causas, um dos resultados de todo este processo é a chegada ao poder de líderes autoritários de extrema 
direita que ameaçam a própria sobrevivência da democracia liberal. Não só no Brasil, mas em vários países do mundo (Lima, 2021a).

Diante das novas circunstâncias históricas, justifica-se hoje a discussão do conceito de comunicação articulado por Freire, pela primeira vez, há mais de 50 anos? O que sua práxis e reflexão posteriores acrescentaram? Como o pensamento comunicacional de Freire tem sido avaliado por pesquisadores brasileiros? E, afinal, Freire tem alguma contribuição a oferecer ao campo da comunicação nos nossos dias? ${ }^{1}$

Para tentar responder a essas perguntas, será necessário retomar sua formulação inicial do conceito. Em Freire, os conceitos de comunicação, educação e cultura estão intimamente associados. Ele próprio, em carta dirigida ao editor da Paz e Terra, Moacyr Felix, no outono de 1970, afirma:

Parece-me interessante salientar ... que a leitura de Extensão ou Comunicação? implica na leitura de Educação como Prática da Liberdade, na da Pedagogia do Oprimido, na de uns tantos artigos que foram publicados pelo Icira com o título de Sobre la Acción Cultural, bem como na de ensaios como Cultural Action for Freedom e The Cultural Action Process - An Introduction to its Understanding, que resultaram de seminários que coordenei no ano passado em Cambridge, Massachusetts. (Freire, 1969/1971a, pp. 9-10)

A formulação inicial do conceito de comunicação em Freire deve ser compreendida, portanto, na perspectiva dos outros textos por ele indicados e no contexto da execução de um programa de reforma agrária no Chile, na metade dos anos 1960. A análise isolada do conceito não só é insuficiente, como resultará sempre incompleta e parcial. A comunicação/educação libertadora de Freire implicava, desde então, a superação da cultura do silêncio na qual os oprimidos estavam imersos.

\section{FUNDAMENTOS DO CONCEITO FREIRIANO DE COMUNICAÇÃO}

A única oportunidade em que Freire discutiu conceitualmente a comunicação foi em ensaio escrito para o Instituto de Capacitación e Investigación en Reforma Agraria (Icira), no Chile, em 1968. O texto pretendia fazer uma crítica às atividades de extensão dos agrônomos e servir de base para discussão em grupo interdisciplinar composto por especialistas ligados ao programa de reforma agrária ${ }^{2}$. Com o sugestivo título de Extensão ou Comunicação? (Freire, 1969/1971a), constitui uma crítica radical à tradição difusionista estadunidense que, na época, tinha grande penetração na América Latina, submetida à rubrica geral de comunicação e desenvolvimento.
${ }^{1}$ Tenho tentado responder a estas questões em diferentes trabalhos, ao longo do tempo. Desta forma, a repetição de argumentos e a duplicação de textos são inevitáveis. Conferir, dentre outros, Lima (2015b e 2021b).
${ }^{2}$ A equipe de especialistas era composta por funcionários da Corporação de Reforma Agrária (Cora), Instituto de Desenvolvimento da Produção Animal (Indap), Serviço de Agricultura e Pecuária (SAG) e Organização das Nações Unidas para Alimentação e Agricultura (FAO). 
${ }^{3}$ Ao tempo deste texto e de outros aqui citados, Freire ainda usava a palavra homem, depois substituída por ser humano. Mantivemos a terminologia do original. $\mathrm{Na}$ autocrítica que faz em Pedagogia da Esperança, ele afirma: "Daquela data até hoje (entre fins de $1970 \mathrm{e}$ começos de 1971) me refiro sempre a mulher e homem ou seres humanos.... Mudar a linguagem faz parte do processo de mudar o mundo. A relação entre linguagempensamento-mundo é uma relação dialética, processual, contraditória. É claro que a superação do discurso machista, como a superação de qualquer discurso autoritário, exige ou nos coloca a necessidade de, concomitantemente com o novo discurso, democrático, antidiscriminatório,

nos engajarmos em práticas também democráticas" (Freire, 1992, p. 68).

${ }^{4}$ No original: "The main difference between the animal, whose activity goes no further than mere production, and man, who creates the domain of culture and history through his action on the world, is that the latter only is a being of praxis. He is a being who creates and knows it as changer and creator. That man, in his permanent relationship with reality, produces not only material goods, sensible things, and objects but also social institutions, ideologies, art, religions, science, and technology".
Contrapondo a comunicação à transmissão, Freire (1969/1971a) argumenta que comunicação é a coparticipação dos Sujeitos no ato de conhecer e que a extensão implica transmissão, transferência, invasão e não comunicação. Freire se afasta, portanto, da falsa neutralidade que normalmente é atribuída à palavra transmissão no difusionismo e em outros modelos de estudo da comunicação, originados na tradição behaviorista. Diz ele:

O termo extensão se encontra em relação significativa com transmissão, entrega, doação, messianismo, mecanicismo, invasão cultural, manipulação etc. E todos esses termos envolvem ações que, transformando o homem ${ }^{3}$ em quase "coisa", o negam como um ser de transformação do mundo. Negam [também] a formação e a constituição do conhecimento autêntico. Negam a ação e reflexão verdadeiras àqueles que são objetos de tais ações. (p. 22)

\section{A visão de natureza humana}

O que fundamenta o conceito freireano de comunicação é sua visão do ser humano como Sujeito em relação com o mundo, que implica, por sua vez, uma concepção específica das relações entre os homens.

Freire (1976) enfatiza o fato de que "toda prática educacional implica um posicionamento teórico da parte do educador. Este posicionamento, por sua vez, demanda - em algumas ocasiões mais, em outras menos explicitamente numa interpretação do homem e do mundo" (p. 42). O que é válido para a prática educacional se aplica igualmente à prática comunicacional. Por essa razão, Freire sempre reitera uma distinção entre homens e animais em seu relacionamento com o mundo que implica um tipo particular de relação entre os homens.

Partindo do pressuposto de que os homens se diferenciam dos animais porque são capazes de criar e inovar seu mundo, Freire (1970b) diz:

A diferença fundamental entre o animal, cuja atividade não vai além da mera produção, e o homem, que cria o domínio da cultura e a história através de sua ação no mundo, é que apenas o último é um ser de práxis. Um ser que cria e que se sabe um transformador e criador. O homem, em sua permanente relação com a realidade, produz não apenas bens materiais, coisas sensíveis e objetos, mas também instituições sociais, ideologias, arte, religiões, ciências e tecnologia ${ }^{4}$. (pp. 167-168)

Freire se utiliza, portanto, da relação do homem com a natureza - a que ele chama de práxis - para explicar o tipo de criação que é exclusivo dos seres humanos, usando a palavra contatos para identificar as relações entre os animais e 
o mundo. Definem-se, assim, as categorias que identificam cada um desses tipos de vínculos com o mundo: (1) relações homens-mundo: postura crítica, pluralidade, consequência e transcendência; (2) contatos animal-mundo: ausência de postura crítica, singularidade, inconsequência e imanência (Freire, 1970c, p. 1, 5). Um belo resumo dessa distinção está apresentado nas primeiras páginas de Educação como Prática da Liberdade:

Os homens se relacionam com seu mundo de uma maneira crítica. A captação que fazem dos dados objetivos de sua realidade (como dos laços que prendem um dado a outro, ou um fato a outro) é naturalmente crítica, por isso, reflexiva e não reflexa, como seria na esfera dos contatos. E no ato da percepção crítica, os homens descobrem a sua própria temporalidade.... Transcendendo a unidimensionalidade, remontam ao ontem, reconhecem o hoje e chegam ao amanhã.... O homem ... existe no tempo. Está dentro. Está fora. Herda. Incorpora. Modifica. Porque não está preso a um tempo reduzido, a um hoje permanente; esmaga-o, emerge dele. Banha-se nele. Temporaliza-se. Na medida, porém, em que faz esta emersão do tempo, libertando-se de sua unidimensionalidade, discernindo-a, suas relações com o mundo impregnam-se de um sentido consequente. A posição normal do homem no mundo, visto que não está apenas nele, mas com ele, não se limita à mera passividade. Não estando limitado à esfera natural (biológica), pois participa também da dimensão criativa, o homem é capaz de interferir na realidade para modificá-la. Herdando a experiência adquirida, criando e recriando, integrando-se às condições de seu contexto, respondendo a seus desafios, objetivando-se a si próprio, discernindo, transcendendo, lança-se o homem num domínio que lhe é exclusivo - o da História e o da Cultura. (Freire, 1967/1971b, pp. 39-41)

Assim, na visão de Freire, enquanto os animais são seres de contatos que se adaptam ao mundo e estão nele, os homens são seres de relações que interagem com o mundo na práxis e estão com ele. Em outro texto, ele completa a visão anterior, assinalando:

Tanto os homens como os animais são seres inacabados, em relação a, ou em contato com, uma realidade igualmente "inacabada". Porém, os homens são seres conscientes de si mesmos e do mundo, ao passo que os animais são seres inconscientes de si mesmos e do mundo. A consciência é uma característica exclusivamente humana, de forma que os homens são "inacabados" num sentido fundamentalmente diferente dos animais. ... Enquanto o homem, ainda que condicionado pelas categorias de tempo e espaço, vive dividido entre o determinismo e a liberdade, os animais são absolutamente determinados por sua espécie e por seu próprio ambiente. 


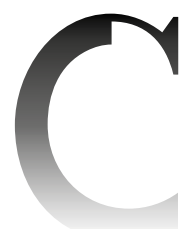

${ }^{5}$ No original: "Men and animals are both unfinished beings, in relation to, or in contact with, an equally 'unfinished' reality. But men are beings conscious of themselves and the world, while animals are beings unconscious of themselves and the world.

Consciousness is an exclusively human characteristic, so that men are 'unfinished' in a way fundamentally different than animals.... While men, even though conditioned by the categories of time and space, live between determinism and liberty, animals are absolutely determined by their species and their own 'support'. Men are not merely unfinished beings; men recognize themselves as incomplete beings, while animals are not capable of asking themselves about themselves".

${ }^{6} \mathrm{~A}$ melhor síntese da concepção de Freire sobre os homens e os animais em sua relação com a natureza e o mundo está nas dez situações existenciais, ilustradas por Francisco Brennand, originalmente discutidas nos círculos de cultura. Conferir "Apêndice", em Freire (1967/1971b). Em Lima (1981/2015b, pp. 114130), discuto essas situações existenciais como conceito antropológico de cultura.

${ }^{7}$ No original: "dialogue, communication, and the I-Thou relationship not as a dimension of the self but as the existential and ontological reality in which the self comes into being and through which it fulfills and authenticates itself".

${ }^{8}$ O Iseb (1955-1964), vinculado ao Ministério de Educação e Cultura, mas com autonomia administrativa, de pesquisa e ensino, tinha como objetivo principal a discussão de uma política pública de desenvolvimento nacional. Extinto após o golpe militar de 1964, teve vários de seus integrantes exilados do Brasil.
Os homens não são apenas seres inacabados; reconhecem-se a si próprios enquanto seres incompletos, ao passo que os animais não são capazes de se fazer perguntas acerca de si próprios ${ }^{5}$. (Freire, 1970c, p. 2/1)

A consequência básica da comparação feita por Freire, e que ele usa com maior frequência, é a de que os homens não são objetos, mas, ao contrário, Sujeitos criativos. Eles podem ser tratados como objetos por sistemas sociais opressivos, isto é, podem ser desumanizados, porém isso não altera sua vocação ontológica, que é a de ser Sujeito, consciente de si mesmo, que interage com o mundo e com outros homens ${ }^{6}$.

\section{A comunicação como realidade existencial e ontológica}

Em sua visão do homem e do mundo, Freire se filia à tradição filosófica que, segundo Friedman (1975), reconhece o "diálogo, a comunicação e a relação Eu-Tu não enquanto uma dimensão do ego, mas como a realidade existencial e ontológica na qual o ego é criado e através da qual satisfaz e autentica a si mesmo"7 (p. xxvii).

Freire recebeu forte influência da filosofia existencialista, tanto através do trabalho do Instituto Superior de Estudos Brasileiros (Iseb) ${ }^{8}$ quanto por seu envolvimento com o cristianismo progressista dos anos 50 e início dos 60 do século passado ${ }^{9}$. É esta influência que faz da comunicação uma categoria central em sua teoria educacional ${ }^{10}$, em sua epistemologia e nas implicações políticas de seu pensamento.

Freire (1969/1971a) argumenta que "o mundo social e humano não existiria como tal se não fosse um mundo capaz de comunicabilidade" e prossegue afirmando que "o mundo humano é, desta forma, um mundo de comunicação" (pp. 65-66). Diz também que "o existir é individual, contudo só se realiza em relação com outros existires. Em comunicação com eles” (Freire, 1967/1971b, p. 41). Mas vai além ao sublinhar: "Somente na comunicação tem sentido a vida humana" (Freire, 1968/1977, p. 73). "Homens como seres não podem ser fora da comunicação, pois que são comunicação. Obstaculizar a comunicação é transformá-los em quase 'coisa"' (Freire, 1968/1977, p. 149).

Mais de 25 anos depois, refletindo sobre a dialogicidade, em seu $\grave{A}$ Sombra desta Mangueira, Freire (1995/2013) reitera e sintetiza:

A dialogicidade é uma exigência da natureza humana, de um lado; de outro um reclamo da opção democrática do educador. No fundo, não há comunicação sem dialogicidade e a comunicação se acha no centro mesmo do fenômeno vital. É neste sentido que a comunicação é, a um tempo, vida, a outro fator de mais vida. (p. 130) 
Considerando o homem como Sujeito criativo em relação com o mundo, e ser essencialmente comunicativo em relação com outros homens, Freire estabelece a base filosófica imediata de seu conceito de comunicação, que inclui necessariamente duas dimensões, a relacional e a política.

\section{A comunicação como relação social e política}

Em sua reflexão sobre $o$ ato de conhecer, Freire (1969/1971a) se baseia na obra do filósofo espanhol-mexicano Eduardo Nicol (1907-1990), que constrói seu argumento no contexto da discussão sobre a natureza do conhecimento científico e da verdade (Nicol, 1965, pp. 42-93). Para ele, além das três relações compreendidas pelo conhecimento - gnosiológica, lógica e histórica - existe uma quarta, também fundamental e indispensável, sem a qual nenhum ato de conhecimento seria possível: a relação dialógica.

Nicol (1965) intercambia a palavra conocimiento (conhecimento) com a palavra pensamiento (pensamento). Em ambos os casos, todavia, refere-se ao fato de que o conhecimento constitui um processo dinâmico e as quatro relações se acham dialeticamente inter-relacionadas. Reivindica, portanto, que, assim como não existe ser humano isolado, também não existe pensamento isolado.

\section{A dimensão relacional}

Apoiado em Nicol (1965), Freire (1969/1971a) argumenta sobre a natureza do conhecimento (e da comunicação) da seguinte forma:

O Sujeito pensante não pode pensar sozinho. Não pode pensar acerca dos objetos sem a coparticipação de outro Sujeito. Não existe um "eu penso", mas sim um "nós pensamos". É o "nós pensamos" que estabelece o "eu penso" e não o oposto. Esta coparticipação dos Sujeitos no ato de pensar se dá na comunicação.... A comunicação implica uma reciprocidade que não pode ser rompida. Portanto, não é possível compreender o pensamento sem referência à sua dupla função: cognitiva e comunicativa.... O que caracteriza a comunicação enquanto este comunicar comunicando-se é que ela é diálogo, assim como o diálogo é comunicativo. A educação é comunicação, é diálogo, na medida em que não é transferência de saber, mas encontro de sujeitos interlocutores que buscam a significação dos significados. (pp. 66-69)

Em outra passagem, é ainda mais incisivo. Exclui a possibilidade da comunicação (e do conhecimento) quando a prática é transmissiva. Diz que "sem a relação comunicativa entre Sujeitos cognoscentes, em torno do objeto cognoscível, desapareceria o ato cognoscitivo" (Freire, 1969/1971a, p. 65). Dessa forma:
${ }^{9}$ Para uma discussão detalhada destas influências, conferir Lima (1981/2015b, capítulo 1)

${ }^{10} \mathrm{Em}$ seus primeiros escritos, Freire chamava seu método de dialógico e utilizava a definição de diálogo encontrada em Karl Jaspers (1953). 


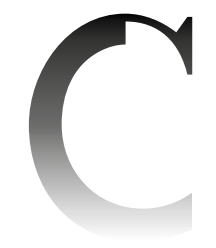

O objeto . . . como conteúdo da comunicação, não pode ser comunicado de um sujeito a outro. Se o objeto do pensamento fosse um puro comunicado, não seria um significado significante mediador dos sujeitos. Se o sujeito "A" não pode ter no objeto o termo de seu pensamento, uma vez que este é a mediação entre ele e o sujeito "B", em comunicação, não pode igualmente transformar o sujeito "B" em incidência depositária do conteúdo do objeto sobre o qual pensa. Se assim fosse - e quando assim é - não haveria nem há comunicação. (Freire, 1969/1971a, pp. 66-67)

Ao enfatizar que a comunicação significa coparticipação dos Sujeitos no ato de pensar, que o objeto de conhecimento não pode se constituir no termo exclusivo do pensamento, mas, de fato, é seu mediador, e que o conhecimento é construído através das relações entre os seres humanos e o mundo, Freire está definindo a comunicação como a situação social em que as pessoas criam conhecimento juntas, transformando e humanizando o mundo. A comunicação é uma interação entre Sujeitos, iguais e criativos. E essa interação deve necessariamente estar fundada no diálogo.

Embora os conceitos de comunicação e diálogo sejam empregados indistintamente, para Freire, “apenas o diálogo comunica realmente" (Freire, 1967/1971b, p. 107). Ele insiste neste ponto, afirmando:

Ser dialógico é não invadir, é não manipular, é não sloganizar. Ser dialógico é empenhar-se na transformação constante da realidade. Esta é a razão pela qual, sendo o diálogo o conteúdo da forma de ser própria à existência humana, está excluído de toda relação na qual alguns homens sejam transformados em "seres para o outro" por homens que são falsos “seres para si”. É que o diálogo não pode travar-se numa relação antagônica. O diálogo é o encontro amoroso dos homens que, mediatizados pelo mundo, o "pronunciam", isto é, o transformam e, transformando-o, o humanizam para a humanização de todos. (Freire, 1969/1971a, p. 43)

Freire (1970c) considera crucial, portanto, que o princípio filosófico

${ }^{11}$ No original: "The real act of knowing is always an act of engagement". do diálogo, ao nível do ato de conhecer, seja realizado no plano social. Insiste que "o verdadeiro ato de conhecer é sempre um ato de engajamento"11 (p. 1/4) e sugere que a comunicação/diálogo não apenas supõe coparticipação e reciprocidade, mas acima de tudo constitui um processo significativo que é compartilhado por Sujeitos, iguais entre si, numa relação também de igualdade. A comunicação deve ser vivida pelos seres humanos como vocação humana. Em outras palavras, a comunicação deve ser vivida em sua dimensão política. 


\section{A dimensão política}

A dimensão política da comunicação aparece de forma mais articulada na Pedagogia do Oprimido (Freire, 1968/1977), no contexto da discussão sobre a dialogicidade e a ação cultural. A comunicação é definida como sendo um encontro entre homens, mediados pela palavra, a fim de dar nome ao mundo. Recorrendo ao mito bíblico do Gênesis, Freire explicita suas raízes religiosas e introduz a ideia de dizer a palavra verdadeira ou dar nome ao mundo enquanto dimensão política específica do diálogo.

Ao analisar o diálogo como fenômeno humano, a palavra surge como essência do próprio diálogo, porém, sustenta Freire (1968/1977), é algo mais que um instrumento que o torna possível. Buscando seus elementos constitutivos, ele encontra duas dimensões - a reflexão e a ação - "numa interação tão profunda que se uma é sacrificada, ainda que em parte, a outra sofre imediatamente" (p. 91). As consequências são, então, o verbalismo - o sacrifício da ação, ou o ativismo o sacrifício da reflexão. Freire afirma, então, que "não há palavra verdadeira que não seja ao mesmo tempo práxis. Assim, dizer a palavra verdadeira é transformar o mundo" (p. 91).

Freire (1968/1977) também se utiliza da noção de dizer a palavra verdadeira em relação ao processo sócio-histórico em que são gerados o pensamento e a linguagem. Para ele, pensamento e linguagem, na medida em que constituem uma totalidade, estão sempre referidos à realidade do sujeito que pensa. O autêntico pensamento-linguagem é gerado na relação dialética entre o sujeito e sua realidade histórica e cultural concreta. Desse modo, no caso das sociedades dependentes ou alienadas culturalmente, o próprio pensamento-linguagem encontra-se alienado porque dissociado da ação implicada pelo pensamento autêntico. Isso gera somente palavras falsas, e não palavras verdadeiras. Freire (1970a) prossegue argumentando que o tema fundamental do "Terceiro Mundo"12 consiste exatamente na "conquista de seu direito à voz, o direito de pronunciar sua palavra" ${ }^{13}$, acrescentando que o homem que "tem voz" é "um homem que é sujeito de suas próprias opções, um homem que projeta livremente o seu próprio destino"14 (pp. 1-4).

Na sequência, Freire (1970a) se mostra ainda mais explícito acerca do significado que atribui à ideia de dar nome ao mundo e, republicanamente, fala em dizer a palavra como "direito humano primordial":

Dizer a palavra (é) um ato humano que implica reflexão e ação. Como tal, trata-se de um direito humano primordial, e não privilégio de uns poucos. Dizer a palavra não é um ato verdadeiro a menos que esteja simultaneamente associado ao direito de autoexpressão e expressão do mundo, de criar e recriar, de decidir e escolher e, em última análise, de participar do processo histórico da sociedade ${ }^{15}$. (p. 12)
${ }^{12} \mathrm{~A}$ expressão Terceiro Mundo surgiu durante a reunião de países asiáticos e africanos emancipados da colonização europeia, na Conferência de Bandung, realizada na Indonésia, em 1955. Ao longo da Guerra Fria, passou a identificar os países que não eram alinhados nem aos Estados Unidos, nem à União Soviética. Posteriormente a expressão foi substituída por países subdesenvolvidos ou em desenvolvimento ou emergentes. Para Freire (1976), todavia, "o conceito de Terceiro Mundo é ideológico e político e não geográfico.... O Terceiro Mundo é o mundo do silêncio, da opressão, da dependência, da exploração, da violência exercida pelas classes dominantes sobre as classes oprimidas" (p. 127).

${ }^{13}$ No original: "the conquest of its right to a voice, of the right to pronounce its word".

${ }^{14}$ Esta citação está na "Introduction" de Freire à monografia Cultural Action for Freedom (Freire, 1970a), que não foi publicada em português. No original: "one who is the subject of his choices, of one who freely projects his own destiny".

${ }^{15}$ Esta é a tradução do original em inglês. Na versão brasileira, a parte final do mesmo texto está ligeiramente modificada. Cf. Freire, 1976, p. 49. No original: "Speaking the word is not a true act if it is not at the same time associated with the right of self-expression and world-expression, of creating and re-creating, of deciding and choosing and ultimately participating in society's historical process". 
Para Freire (1968/1977), a dimensão política da comunicação/diálogo a transformação do mundo ao se dar nome a ele, pronunciá-lo - é inerente à própria natureza humana. À luz dessa realidade, argumenta:

A existência, porque humana, não pode ser muda, silenciosa, nem tampouco pode nutrir-se de falsas palavras, mas de palavras verdadeiras, com que os homens transformam o mundo. Existir, humanamente, é pronunciar o mundo, é modificá-lo. O mundo pronunciado, por sua vez, se volta problematizado aos sujeitos pronunciantes, a exigir deles novo pronunciar. (p. 92)

Resumindo: ao afirmar que a comunicação significa coparticipação dos Sujeitos no ato de pensar; que o conhecimento é construído através das relações entre os seres humanos e o mundo; que o objeto de conhecimento não pode se constituir no termo exclusivo do pensamento, mas, de fato, é seu mediador; que a comunicação é uma interação entre Sujeitos, iguais e criativos, necessariamente fundada no diálogo; que a palavra constitui a essência do diálogo e a palavra verdadeira é práxis comprometida com a justiça e a transformação social; Freire define a comunicação como a situação social em que as pessoas criam conhecimento juntas, transformando e humanizando o mundo. Vale dizer, a verdadeira comunicação será sempre uma comunicação libertadora.

$\mathrm{Na}$ feliz síntese de Ana Maria Araújo Freire (2015):

Partindo ... da análise semântica das palavras, dialogando com elas, [Paulo] entendeu, na contramão da História, que extensão implicando transmissão, transferência, invasão e manipulação era não só diferente, mas antagônica da comunicação. Esta é coparticipação dos sujeitos em torno do objeto que buscam conhecer, quando buscam humanizar-se. A extensão está dentro dos padrões autoritários da verticalidade do mando, enquanto a comunicação se caracteriza pela horizontalidade do diálogo amoroso epistemológico. Uma ordena de cima para baixo, anulando a capacidade de pensar e de decidir de quem fica obrigado(a) a simplesmente obedecer. A outra chama ao diálogo e ao entendimento da relação de equidade entre quem está envolvido(a) na questão, possibilitando o pensar, o decidir e o aprender. Uma arranca a humanidade do outro e da outra, assim impossibilitando que se façam sujeitos transformadores do mundo aeticamente feio e injusto. A outra dá margem à inventividade, à recriação, à humanização. Uma despolitiza. A outra politiza. Uma trabalha pela incomunicabilidade, pela mudez, pela opressão e pela dominação. A outra reforça a relação social de igualdade de oportunidades e de direitos, não esquecendo os deveres. Uma oprime. A outra liberta. (p. 13) 


\section{OUTROS ESCRITOS DE FREIRE}

Depois de Extensão ou Comunicação? (1969/1971a), Pedagogia do Oprimido (1968/1977) e outros textos do mesmo período, Freire não mais tratou conceitualmente o tema da comunicação. Ainda na Pedagogia do Oprimido, quando discute "a conquista" como uma das características da teoria da ação antidialógica, Freire (1968/1977) diz que a "aproximação" com as massas para mantê-las alienadas "não pode ser feita pela comunicação, se faz pelos comunicados, pelos depósitos dos mitos indispensáveis à manutenção do status quo". Ele considera que os "meios de comunicação" são os canais de propaganda organizada que levam às massas populares os mitos necessários à sua conquista, "como se o depósito deste conteúdo alienante nelas fosse realmente comunicação" (pp. 163-164).

Registro três outras ocasiões emblemáticas em que Freire faz referência a formas tecnologicamente mediadas de comunicação, em particular à televisão, duas delas respondendo a perguntas a ele formuladas.

A primeira, está no segundo volume do livro dialogado com Sérgio Guimarães, Sobre a Educação (Freire, \& Guimarães, 1984):

SÉRGIO: ... A gente vê que, nos seus vários livros, você não chegou a discutir propriamente as questões [dos meios de comunicação]. Por quê?

FREIRE: Exatamente porque nunca me senti competente, a não ser do ponto de vista de uma apreciação global. Se me perguntas: "Paulo, o que é que você acha da televisão?", eu te respondo: para mim, a televisão não pode ser compreendida em si. Ela não é um instrumento puramente técnico, o uso dela é político. E sou capaz também de fazer algumas propostas com relação ao uso da televisão. Mas, mesmo quando não venho tratando desses chamados meios de comunicação em trabalhos meus anteriores, mesmo quando não falo diretamente sobre eles, eu os considero, por exemplo, dentro do horizonte geral da teoria do conhecimento que venho desenvolvendo nos meus trabalhos sobre educação [ênfase adicionada]. Não os trato diretamente, no sentido de que eles não são objeto de um estudo técnico, cientificamente válido. . . . Não me sinto um especialista em torno desse tema. Eu o abordo em linhas gerais. (p. 40)

A segunda passagem está em longa entrevista que Freire concede a Sonia Breccia, no programa Hoy por Hoy, do Canal 5, a TV estatal uruguaia, em junho de 1989. Fiz uma seleção editada de alguns trechos representativos de sua transcrição que aparece em Pedagogia do Compromisso (Freire, 2008): 
ENTREVISTADORA: Como a TV é utilizada no seu país e como o sr. pensa que ela poderia ser utilizada? O sr. gosta de TV? A TV tem ou não um papel (no processo) de mudança?

FREIRE: Procuro ser um homem e um educador do meu tempo. Não posso compreender como um educador deste tempo pode negar a TV, negar o vídeo, negar a computação, negar o rádio.... Adoraria trabalhar na TV, provavelmente teria que aprender muito porque não sei nada sobre isso. . . . Acredito que este mundo de ilusão é fascinante, mas se existe um mundo de ilusão que é profundamente real é este. .. . Através do imaginário, vocês tocam o real. Existe uma relação enorme entre o imaginário e o real, o concreto. Entretanto, para este trabalho na TV, é preciso saber que não existe TV neutra. Um meio de comunicação como este não pode deixar de ser eminentemente político e ideológico. ... Provavelmente, se eu trabalhasse em Montevidéu permanentemente, não teria quatro programas como este. Não por sua causa, mas por causa das forças político-ideológicas que estão por trás da TV, por trás das câmeras.

ENTREVISTADORA: O sr. confia tanto na importância do meio, na inteligência das pessoas e na sua capacidade de transmitir para saber que ..., por cima dos interesses particulares ..., existe um entrevistado e uma inteligência popular que podem ultrapassar (esses interesses)?

FREIRE: Eu acredito que existe, eu aposto nisso, como educador e como político.... E meu sonho é que um dia a TV trate o povo com decência. Você sabe que me irritam profundamente as pessoas que fazem de maneira "científica", neutra, que trabalham na organização dos noticiários. Às vezes parece que não sabem o que estão fazendo. Juntam um monte de notícias do mundo inteiro e as "pulverizam". .. Isso é sabedoria ideológica e política da classe dominante e isto acontece no mundo inteiro, não só no Brasil.

ENTREVISTADORA: O sr. pensa que a TV é todo-poderosa, de tal maneira que faz os homens menos livres e nos "vendem" o candidato ou a fórmula que querem?

FREIRE: Não, não é assim. Acredito que é um poder inegável, indiscutível, mas não tão potente como se pensava.... A TV é um extraordinário meio de comunicação, mas é preciso que ensinemos, que aprendamos a vê-la com criticidade. ... O fundamental é lutar para que este meio seja mais ético, que esteja mais a serviço dos explorados, dos dominados e para isso temos que mudar a própria sociedade e ao mudar a sociedade a questão ética e política que se propõe é não perpetuar 
neste meio de comunicação o gosto pela preservação, pelo status quo. Ou seja, em uma sociedade diferente, colocar este meio a serviço de torná-lo diferente: mais vivo e mais criativo. (pp. 127-139)

E a terceira aparece em um dos últimos escritos de Freire, Pedagogia da Autonomia (1997), quando trata da necessidade de "desocultar verdades escondidas" na mídia:

Pensar em televisão ou na mídia em geral nos põe o problema da comunicação [de massa], processo impossível de ser neutro. Na verdade, toda comunicação [de massa] é comunicação de algo, feita de certa maneira em favor ou na defesa, sutil ou explícita, de algum ideal contra algo e contra alguém, nem sempre claramente referido. Daí também o papel apurado que joga a ideologia na comunicação [de massa], ocultando verdades, mas também a própria ideologização do processo comunicativo. Seria uma santa ingenuidade esperar de uma emissora de televisão do grupo do poder dominante que, noticiando uma greve de metalúrgicos, dissesse que seu comentário se funda nos interesses patronais. Pelo contrário, seu discurso se esforça para convencer que sua análise da greve leva em consideração os interesses da nação. Não podemos nos pôr diante de um aparelho de televisão "entregues" ou "disponíveis" ao que vier.... A postura crítica e desperta nos momentos necessários não pode faltar.... Para enfrentar o ardil ideológico de que se acha envolvida a mensagem [do poder dominante] na mídia ... nossa mente ou nossa curiosidade teria que funcionar epistemologicamente todo o tempo. E isso não é fácil. (pp. 157-158)

Em resumo: o que se observa nas citações acima é que Freire reconhece o imenso poder dos meios de comunicação de massa para a criação do imaginário coletivo; seu poder de difundir os mitos que mantêm as massas alienadas; a impossibilidade de serem neutros; o imenso poder político e ideológico, em particular da televisão. Por outro lado, não perde a crença na capacidade de mulheres e homens educados para lidar criticamente com os meios. Acima de tudo, Freire remete o(a) leitor(a) para suas reflexões anteriores sobre a teoria do conhecimento e para a necessidade de se pensar epistemologicamente, vale dizer, considerar a matriz dialógica como referência normativa para o processo de comunicação, seja ela mediada tecnologicamente ou não.

\section{O QUE PENSAM OS ESTUDIOSOS BRASILEIROS?}

No ensaio "A Pesquisa em Comunicação na América Latina", ao identificar o que chama de "pais fundadores", Christa Berger (2001) menciona levantamento realizado entre 50 pesquisadores da região, em 1992. O estudo 
aponta Paulo Freire como uma das cinco principais influências teóricas deste campo de estudo. Freire é lembrado por seu ensaio Extensão ou Comunicação? (1969/1971a), no qual "está contida a crítica principal aos meios de comunicação de massa: de consistirem em meros instrumentos de transmissão, de tratarem os destinatários como receptores passivos e de impossibilitarem relações dialógicas" (Berger, 2001, p. 256). Da mesma forma, autores amplamente reconhecidos e com vasta produção no campo, como o belga Armand Mattelart - com experiência histórica no Chile dos anos 1960 e 1970 - e o espanhol/colombiano Jesús Martín-Barbero, reconhecem a contribuição de Freire na construção de suas perspectivas teóricas.

Denise Cogo (1999), por outro lado, descreve a presença ativa das ideias de Freire em três áreas: os estudos e a prática da comunicação rural; a comunicação alternativa e/ou popular e os estudos culturais, nas vertentes de pesquisa sobre o receptor ativo e a leitura crítica da mídia.

Com relação à comunicação alternativa e/ou popular e comunitária, vale registrar a pesquisa recente de Cicilia Peruzzo (2017) que, depois de acompanhar a prática de diferentes organizações comunitárias e movimentos populares em três estados brasileiros - Paraíba, Paraná e São Paulo -, afirma:

Paulo Freire . . contribuiu muito na formulação de conceitos e nas práticas de comunicação popular, alternativa e comunitária - ou horizontal, participativa na América Latina. Muitos autores latino-americanos que tratam dessa comunicação, bem como da comunicação para o desenvolvimento e mudança social e das relações entre Educação e Comunicação, se fundamentam em concepções de Paulo Freire ou, pelo menos, partiram de suas ideias. As práticas sociais, por sua vez, ecoam em diferentes regiões e experiências, os princípios do diálogo, do protagonismo popular, da participação horizontal, da criticidade e de educação emancipadora, principalmente, em se tratando da educação não formal e informal. . . . Os conceitos da comunicação popular e comunitária e suas denominações derivadas, trazem em seu âmago alguns dos princípios da educação libertadora de Paulo Freire, os quais podem ser percebidos em estudiosos dessa vertente comunicacional, a exemplo de Mário Kaplún, Luis Ramiro Beltrán, Daniel Prieto Castillo, Juan Diaz Bordenave, Alfonso Gumucio Dagron, Rosa Maria Alfaro, Regina Festa, a própria autora e muitos outros. Também é comum que as lideranças e militantes levem adiante essas proposições colocando em prática os referidos princípios. (pp. 8-9)

Por outro lado, considerando que Freire foi o precursor do diálogo crítico, mais ou menos explícito, com as nascentes tradições norte-americana e inglesa dos estudos culturais, personificadas, à época, em James W. Carey (1934-2006) 
e Raymond Williams (1921-1988) ${ }^{16}$; merecem registro as ponderações de Cogo (1999) sobre sua importância fundadora para esta tradição na América Latina. Afirma ela:

A obra de Paulo Freire ajuda a consolidar as bases para o entendimento das inter-relações entre comunicação, educação e cultura, cujos desdobramentos refletem-se, mais tarde, no desenvolvimento de uma vertente denominada de estudos culturais e comunicação. Herdeira dos estudos culturais ingleses, essa vertente encontra sua especificidade no contexto latino-americano a partir do final da década de 80 através de investigadores como o colombiano Jesús Martín-Barbero e os mexicanos [sic] Nestor García Canclini e Guillermo Orozco Gómez, cujas reflexões apontam para a construção de uma trajetória comum: a compreensão da comunicação no marco do processo das culturas em que a compreensão do fenômeno comunicativo não se esgota em conceitos e critérios como canais, meios, códigos, mensagens, informação. O entendimento da comunicação é reorientado a uma revalorização do universo cultural e do cotidiano dos sujeitos como mediadores dos sentidos produzidos no campo da recepção das mensagens difundidas pelos meios massivos de comunicação. (p. 31)

Outro autor que destaca o potencial da obra de Freire para os estudos de comunicação é Eduardo Meditsch (2008). Em instigante artigo publicado em 2008 ele chama a atenção para o compromisso de Freire com a prática:

O pensamento de Paulo Freire não era limitado por esta ou aquela escola teórica em que, eventualmente, se apoiava: seu compromisso primeiro era com a vida real, com a realidade humana que procurava compreender para transformar ou, numa palavra, com a prática. (Meditsch, 2008, p. 3)

Tanto Cogo (1999) quanto Meditsch (2008), no entanto, lembram não só as leituras reducionistas e o aprisionamento "no jogo dos conceitos praticado no meio acadêmico", como também "a débil apropriação" que se faz da obra freiriana nos estudos de comunicação. Meditsch (2008), em cáustico diagnóstico sobre o campo de estudos em nosso país, afirma que foi exatamente o primado fundamental da prática que provocou o distanciamento de Freire:

Os "práticos" nunca se deram conta do potencial da teoria freireana para aperfeiçoar as suas práticas, e a grande maioria nem tomou conhecimento de suas ideias, a não ser por orelhas de livro. Por sua vez, os "teóricos" que leram além das orelhas jamais se sentiram compromissados a aplicar as ideias de Freire nas práticas midiáticas, não apenas por ignorarem solenemente estas práticas, mas também por sentirem
${ }^{16}$ Para uma discussão destas questões, conferir Lima (1981/2015b), especialmente o capítulo IV. 


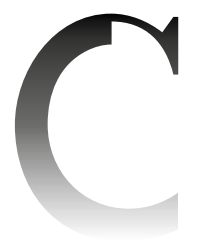

${ }^{17}$ Ao contrário da defesa de uma inocente pureza epistemológica para o campo de estudos da comunicação, Stuart Hall (1989) argumentou, em seu "Ideology and Communication Theory", sobre a inevitabilidade da articulação teórica da comunicação acontecer no campo regional "das estruturas e práticas sociais" (cf. Lima, 2015a, pp. 103-133).

um profundo desprezo por elas. Para estes, a prática de que falavam Marx e Freire era apenas mais um conceito a enriquecer sua bagagem teórica, ou era uma prática tão idealizada que se recusava a admitir como legítima a realidade com que "os práticos" se relacionavam. Desta forma, as ideias de Freire, quando levadas em conta em nossa área, foram confinadas ao "balé de conceitos" da comunicologia e "domesticadas" pela lógica acadêmica que seu autor sempre condenou. A sua aplicação no desenvolvimento das práticas da comunicação foi abortada em nosso campo. (p. 8)

Para além das observações de Meditsch (2008), há também autores que consideram o pensamento de Freire um desserviço ao campo de estudos da comunicação, sobretudo à busca teórica de um objeto de estudo específico da própria comunicação ${ }^{17}$. Um destes autores descarta a eventual contribuição do "pedagogo" Freire e critica, de uma posição pretensamente "científica", sua inclusão entre os quatro "pais fundadores" de uma "escola latino-americana de comunicação", cuja existência não reconhece. Afirma:

A teoria foi, e em grande medida continua sendo, o grande ponto fraco da produção latino-americana - de onde o paradoxo de classificá-la como uma escola. Uma prova disso é que autores de outras disciplinas frequentemente são apontados como pais fundadores ou como os grandes teóricos de nossa área. Paulo Freire, por exemplo, bastante reconhecido como pedagogo, acaba se tornando um dos quatro principais teóricos latino-americanos da comunicação, ainda que a real contribuição deste autor seja bastante discutível: sua visão humanista e filosófica da comunicação se deixa melhor expressar em uma teologia que toma o amor divino como fundamento e critério último da comunicação. Claro que isto só pode se dar com a entrada em cena de um conceito de comunicação com abrangência estratosférica e pouco propício à discussão científica. (Martino, 2007, pp. 107-108)

As mencionadas observações de Berger (2001), Cogo (1999), Peruzzo (2017) e Meditsch (2008), além de outras de importantes autores por eles(as) citados, respondem afirmativamente à questão se Freire, afinal, teria alguma contribuição a oferecer ao campo da comunicação nos nossos dias. Não se examina aqui todos os autores que se referem a Freire, mas são raros os que argumentam de forma contrária.

\section{CONTRIBUIÇÕES DE FREIRE}

De forma complementar, é ainda possível sugerir pelo menos quatro áreas específicas dos estudos de comunicação para as quais certamente Freire teria algo relevante a dizer. 


\section{Comunicação como diálogo}

Freire é o principal representante contemporâneo da tradição teórica da comunicação como diálogo. É o que sustenta Clifford Christians $(1988,1991)$, um dos mais importantes pesquisadores dessa tradição nos Estados Unidos. Freire acrescenta a esta tradição a dimensão política, ausente das reflexões de seus principais expoentes (cf. Lima \& Christians, $1979 \mathrm{a}^{18}$ ).

Ainda em 2001 escrevi:

${ }^{18}$ Versão em língua portuguesa publicada em Lima e

Christians (1979b).

se até recentemente esse modelo parecia inadequado para qualquer tipo de aplicação no contexto da chamada "comunicação de massa", unidirecional e centralizada, hoje a nova mídia reabre as possibilidades de um processo dialógico mediado pela tecnologia.... O modelo normativo construído por Freire ganha atualidade e passa a servir de ideal para a realização plena da comunicação humana em todos os seus níveis. (Lima, 2001/2012, p. 53)

A tradição da comunicação como diálogo ganha renovada importância diante da possibilidade de interação permanente e on-line no ato mesmo da comunicação. Freire teorizou ética e normativamente a comunicação interativa antes da revolução digital, vale dizer, antes da internet e de suas redes sociais. Como fez o próprio Freire, devemos nos remeter a suas reflexões sobre a teoria do conhecimento, referência básica do conceito de comunicação como diálogo. Lá encontraremos uma referência ética e normativa revitalizada, criativa e desafiadora de imensa valia para pensar as novas tecnologias de comunicação e as políticas públicas necessárias e adequadas a sua complexa regulação democrática.

\section{Comunicação e liberdade (libertação)}

A concepção implícita de liberdade na definição dialógica de comunicação elaborada por Freire é constitutiva de uma cidadania ativa que equaciona autogoverno com participação política, contrariamente à liberdade negativa do liberalismo clássico. A liberdade não antecede à política, mas se constrói a partir dela. A educação (comunicação) deve ser uma prática da liberdade. Ter voz e manifestá-la publicamente, em igualdade de condições com qualquer outra cidadã ou cidadão, é condição necessária ao processo democrático. $\mathrm{O}$ sujeito-cidadão constitui o eixo principal da vida pública democrática.

Em seminário sobre alfabetização e cidadania, realizado em Maceió, Sergipe, em novembro de 1990, Freire (2001) afirmou: 


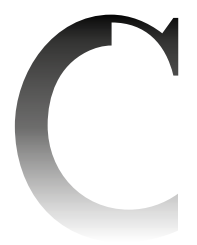

${ }^{19}$ Agradeço ao professor Murilo C. Ramos (FAC-UnB) por ter chamado minha atenção para a citação de Freire por Schudson.

${ }^{20}$ No original: "the right of self-expression and worldexpression".
Ser cidadão passa pela participação popular, pela voz. Quando digo voz não é abrir a boca e falar, recitar. A voz é um direito de perguntar, criticar, de sugerir. Ter voz é isso. Ter voz é ser presença crítica na história. Ter voz é estar presente, não ser presente. (pp. 130-131)

Esse aspecto republicano do pensamento de Freire não passou despercebido ao renomado historiador da imprensa, Michael Schudson. Em seu famoso Descobrindo a Notícia: Uma História Social dos Jornais nos Estados Unidos, ao discutir as explicações correntes sobre a revolução ocorrida no jornalismo estadunidense a partir da década de 1830, Schudson (2010) recorre a Freire para contestar "o argumento da alfabetização" (pp. 48-52)19.

Apesar de admitir, por óbvio, que sem a alfabetização os jornais de grande circulação seriam inviáveis, ele questiona se o aumento da alfabetização seria em si um estímulo para a circulação dos jornais e afirma que existem boas razões para se duvidar disso. Schudson (2010) cita a passagem de Freire sobre o "direito de autoexpressão e expressão do mundo" ${ }^{20}$ (Freire, 1970a, p. 12) e continua argumentando que

o que explicaria um aumento na alfabetização em uma sociedade letrada, seria uma extensão dos diretos políticos e econômicos ou, de modo mais amplo, uma extensão, a um número maior de indivíduos, da consciência de que eles são atores da história. (Schudson, 2010, p. 50)

Em seguida, acrescenta ainda a importância de "toda a gama de mudanças sociais, muitas delas políticas, que possibilitam às pessoas emergir daquilo que Freire denomina a 'cultura do silêncio"' (Schudson, 2010, p. 52) para, então, concluir que "a alfabetização é uma condição necessária, mas insuficiente, para o crescimento da circulação de jornais" (Schudson, 2010, p. 52).

\section{Comunicação e direitos humanos}

As ideias de Freire constituem a base teórica para a positivação da comunicação como direito humano fundamental.

$\mathrm{O}$ direito à comunicação perpassa as três dimensões da cidadania liberal definidas por T. H. Marshall, em seu clássico Cidadania, Classe Social e Status (1949/1967), cada uma delas fundada em um princípio e uma base institucional distintos. Na verdade, contrariando a lógica liberal, o direito à comunicação se constitui, ao mesmo tempo, em direito civil - liberdade individual de expressão; em direito político - através do direito à informação; e em direito social - através 
do direito a uma política pública garantidora do acesso do cidadão às diferentes formas de comunicação mediadas tecnologicamente.

A necessidade do desenvolvimento e da positivação de um direito à comunicação foi identificada há mais de 50 anos pelo francês Jean D’Arcy, quando diretor de serviços audiovisuais e de rádio do Departamento de Informações Públicas das Nações Unidas, em 1969. Naquela época, ele afirmava:

Virá o tempo em que a Declaração Universal dos Direitos Humanos terá de abarcar um direito mais amplo que o direito humano à informação, estabelecido pela primeira vez 21 anos atrás no Artigo 19. Trata-se do direito do homem de se comunicar (citado em Fisher, 1984, p. 26).

Onze anos depois, o famoso Relatório MacBride, publicado pela Unesco (1980/1983), reconhecia pioneiramente o direito à comunicação. Diz o Relatório:

Hoje em dia se considera que a comunicação é um aspecto dos direitos humanos. Mas esse direito é cada vez mais concebido como o direito de comunicar, passando-se por cima do direito de receber comunicação ou de ser informado. Acredita-se que a comunicação seja um processo bidirecional, cujos participantes - individuais ou coletivos - mantêm um diálogo democrático e equilibrado. Essa ideia de diálogo, contraposta à de monólogo, é a própria base de muitas das ideias atuais que levam ao reconhecimento de novos direitos humanos. $\mathrm{O}$ direito à comunicação constitui um prolongamento lógico do progresso constante em direção à liberdade e à democracia. (pp. 287-291)

Tanto a proposta de D’Arcy como o Relatório MacBride, na verdade, assumiam e consagravam a perspectiva dialógica da comunicação que já havia sido elaborada por Freire, do ponto de vista conceitual, em Extensão ou comunicação? (1969/1971a). A comunicação como característica da natureza humana, coparticipação de sujeitos iguais que se relacionam dialogicamente em torno do objeto que querem conhecer e, ao mesmo tempo, transformam o mundo no contexto da ação cultural libertadora.

Desde o final da década de 1960, como já citado, Freire afirmava que dizer a palavra, ter voz, se autoexpressar constituía um "direito humano primordial". Vale repetir:

Dizer a palavra (é) um ato humano que implica reflexão e ação. Como tal, trata-se de um direito humano primordial [ênfase adicionada], e não privilégio de uns poucos. Dizer a palavra não é um ato verdadeiro a menos que esteja simultaneamente 


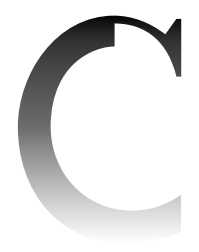

${ }^{21}$ No original: "Speaking the word really means: a human act implying reflection and action. As such it is a primordial human right and not the privilege of a few. Speaking the word is not a true act if it is not at the same time associated with the right of self-expression and world-expression, of creating and re-creating, of deciding and choosing and ultimately participating in society's historical process".

${ }^{22} \mathrm{~A}$ perspectiva freiriana é descrita e elaborada por Pedrinho Guareschi (2013).

${ }^{23}$ Aos eventuais interessadas/os, tomo a liberdade de sugerir a leitura de Lima (2021b). associado ao direito [ênfase adicionada] de autoexpressão e expressão do mundo, de criar e recriar, de decidir e escolher e, em última análise, de participar do processo histórico da sociedade ${ }^{21}$. (Freire, 1970a, p. 12)

A comunicação é necessariamente dialógica, de mão dupla, abrigando, ao mesmo tempo, os direitos de informar e ser informado e o direito de acesso aos meios tecnológicos necessários à plena liberdade de expressão ${ }^{22}$.

\section{Comunicação e cultura do silêncio ${ }^{23}$}

Existe um enorme potencial analítico em conceitos elaborados por Freire que não foram ainda plenamente explorados. Um exemplo eloquente é o conceito de cultura do silêncio - a cultura que hospeda aqueles que não têm voz - e o seu corolário, as políticas de silenciamento.

A relação entre comunicação e cultura se dá em Freire de maneira bastante simples: não há possibilidade de comunicação na cultura do silêncio. Nela predomina o mutismo da opressão. A ação cultural, isto é, o processo consciente de luta pela libertação humana, assumido por mulheres e homens que são sujeitos de sua própria História, é o espaço da comunicação dialógica, geradora de conhecimento novo e de transformação social.

\section{CONSIDERAÇÕES FINAIS}

Partindo do desafio concreto que emerge de sua prática com camponeses no processo de reforma agrária no Chile, dos anos 1960, Freire faz uma crítica rigorosa da extensão rural, que se baseava na teoria da difusão de inovações. Desenvolve, então, a alternativa teórica e prática da comunicação dialógica humanizadora e libertadora. Ela se situa no polo oposto da comunicação como transmissão e se funda na crença do ser humano como sujeito criador e transformador do mundo, e em uma teoria gnosiológica na qual, sem o diálogo (comunicação) entre iguais, não se produz conhecimento. A comunicação passa a ser, por definição, necessariamente política e libertadora.

Embora existam críticas pontuais a seu pensamento, Freire influenciou e continua a influenciar importantes pesquisadores da comunicação no Brasil e no exterior, inclusive formuladores, em organismos multilaterais, da perspectiva da comunicação como direito humano fundamental.

A proposta de uma comunicação libertadora freiriana, alongamento de todo um pensamento e uma práxis voltados para a prática da liberdade, 
continua oferecendo uma perspectiva criativa e desafiadora para o campo de estudos da comunicação, sobretudo como referência normativa e ética nas circunstâncias históricas desta terceira década do século XXI, dominada pela interatividade virtual, tornada possível pela revolução digital e pela internet. |MI

\section{REFERÊNCIAS}

Berger, C. (2001). A pesquisa em comunicação na América Latina. In A. Hohlfeldt, Luiz C. Martino \& V. V. França (Orgs.), Teorias da comunicação: Conceitos, escolas e tendências (pp. 241-277). Vozes.

Christians, C. (1988). Dialogic communication theory and cultural studies. In N. Dezin (Ed.), Studies in symbolic interaction (Vol. 9, pp. 3-31). JAI Press. Christians, C. (1991). Paulo Freire's emancipatory strategy. In J. C. Pitt \& E. Lugo (Eds.), The technology of discovery and the discovery of technology (pp. 271-287). The Society for Philosophy and Technology.

Cogo, D. (1999). Da comunicação rural aos estudos de audiência: Influência da obra de Paulo Freire no ensino e na pesquisa em comunicação social. Rastros - Revista do Ielusc, 1(1), 29-36.

da Empoli, G. (2019). Os engenheiros do caos: Como as fake news, as teorias da conspiração e os algoritmos estão sendo utilizados para disseminar ódio, medo e influenciar eleições. Vestígio.

Fisher, D. (1984). O direito de comunicar: Expressão, informação e liberdade. Brasiliense.

Freire, A. M. A. (2015). Prefácio. In V. A. Lima, Comunicação e cultura: As ideias de Paulo Freire (2a ed., pp. 9-15). EdUnB; Editora Fundação Perseu Abramo. Freire, P., \& Guimarães, E. (1984). Sobre a educação: Diálogos (Vol. II). Paz e Terra. Freire, P. (1970a). Cultural action for freedom. Harvard Educational Review; Centre for the Study of Development and Social Change.

Freire, P. (1970b). Cultural freedom in Latin America. In L. M. Colonnese (Ed.), Human rights and the liberation of man in the Americas (pp. 162-179). University of Notre Dame Press.

Freire, P. (1970c). Cultural action: A dialectic analysis (Cuaderno n. 1004). Cidoc. Freire, P. (1971a). Extensão ou comunicação? Paz e Terra. (Trabalho original publicado em 1969)

Freire, P. (1971b). Educação como prática da liberdade (3a ed.). Paz e Terra. (Trabalho original publicado em 1967)

Freire, P. (1976). Ação cultural para a liberdade e outros ensaios. Paz e Terra.

Freire, P. (1977). Pedagogia do oprimido (4a ed.). Paz e Terra. (Trabalho original publicado em 1968). 
Freire, P. (1992). Pedagogia da esperança: Um reencontro com a pedagogia do oprimido. Paz e Terra.

Freire, P. (1997). Pedagogia da autonomia. Paz e Terra.

Freire, P. (2001). Pedagogia dos sonhos possíveis (A. M. A. Freire, Org.). Editora Unesp.

Freire, P. (2008). Pedagogia do compromisso: América Latina e educação popular (A. M. A. Freire, Org.). Villa das Letras.

Freire, P. (2013). À sombra desta mangueira (11a ed.). Paz e Terra. (Trabalho original publicado em 1995)

Friedman, M. (1975). Introduction. In M. Buber, Between man and man (pp. xi-xx). MacMillan.

Guareschi, P. (2013). O direito humano à comunicação: Pela democratização da mídia. Vozes.

Hall, S. (1989). Ideology and communication theory. In B. Dervin, L. Grossberg, B. O’Keefe \& E. Wartella (Eds.), Rethinking communication. Paradigm issues (Vol. 1, pp. 40-52). Sage.

Jaspers, K. (1953). The origin and goal of history. Yale University Press.

Lima, V. A. (2012). Mídia: Teoria e política (2a ed.). Editora Fundação Perseu Abramo. (Trabalho original publicado em 2001)

Lima, V. A. (2015a). Cultura do silêncio e democracia no Brasil: Ensaios em defesa da liberdade de expressão (1980-2015). EdUnB.

Lima, V. A. (2015b). Comunicação e cultura: As ideias de Paulo Freire (2a ed.). EdUnB; Editora Fundação Perseu Abramo. (Trabalho original publicado em 1981)

Lima, V. A. (2021a). Notas sobre "política quântica” e tradicionalismo: Cultura, política e comunicação em tempos de Bolsonaro. In A. A. C. Rubim \& M. Tavares (Orgs.), Cultura e política no Brasil atual (pp. 109-129). Editora Fundação Perseu Abramo. https://bit.ly/3zH7wod

Lima, V. A. (2021b). Paulo Freire: A prática da liberdade, para além da alfabetização. Editora Fundação Perseu Abramo; Autêntica.

Lima, V. A., \& Christians, C. (1979a). Paulo Freire: The political dimension of dialogic communications. Communication, 4(1), 133-155.

Lima, V. A., \& Christians, C. (1979b). Paulo Freire: A dimensão política da comunicação dialógica (C. N. Coutinho, Trad.) Síntese, 6(16), 111-130.

Löwy, M. (2016). O que é Cristianismo da Libertação: Religião e política na América Latina (2a ed.). Editora Fundação Perseu Abramo; Expressão Popular.

Marshall, T. H. (1967). Cidadania, classe social e status. Zahar. (Trabalho original publicado em 1949) 
Martino, L. C. (2007). Escola latino-americana de comunicação: Equívoco teórico e político. Revista Latinoamericana de Ciencias de la Comunicación, $4(6), 102-112$.

Meditsch, E. (2008). Paulo Freire e o estudo da mídia: Uma matriz abortada. Biblioteca On-Line de Ciências da Comunicação. https://bit.ly/3AEAUx1

Nicol, E. (1965). Los principios de la ciencia. Fundo de Cultura Económica.

Peruzzo, C. M. K. (2017). Ideias de Paulo Freire aplicadas à comunicação popular e comunitária. Revista Famecos, 24(1), ID24207. https://doi. org/10.15448/1980-3729.2017.1.24207

Schudson, M. (2010). Descobrindo a notícia: Uma história social dos jornais nos Estados Unidos. Vozes.

Unesco (1983). Um mundo e muitas vozes: Comunicação e informação na nossa época. Editora da Fundação Getúlio Vargas. (Trabalho original publicado em 1980)

Artigo recebido em 3 de junho e aprovado em 30 de junho de 2021. 